\title{
Molecular epidemiology of HIV-1 clades in Southern Brazil
}

\author{
Sonia Mara Raboni ${ }^{1}$, Sérgio Monteiro de Almeida ${ }^{1 /+}$, Indianara Rotta ${ }^{1}$, Cléa Elisa Lopes Ribeiro ${ }^{1,2}$, \\ Debra Rosario $^{3}$, Luine Rosele Vidal', Meri Bordignon Nogueira', Maristela Riedel ${ }^{4}$, \\ Maria da Graça Winhescki ${ }^{4}$, Kátia Antunes Ferreira', Ronald Ellis ${ }^{3}$
}

\author{
'Laboratório de Virologia, Hospital de Clínicas, Universidade Federal do Paraná, Rua Padre Camargo 280 sala 202, 80060-240 Curitiba, PR, Brasil \\ ${ }^{2}$ Centro de Epidemiologia, Secretaria Municipal de Saúde, Curitiba, PR, Brasil \\ ${ }^{3}$ University of California, San Diego, USA ${ }^{4}$ Laboratório da Secretaria Municipal de Saúde, Curitiba, PR, Brasil
}

Human immunodeficiency virus (HIV) clades B and C account for more than $60 \%$ of the HIV-1 infections worldwide. In this paper, we describe the profiles of patients infected with subtypes of HIV-1 from the state of Paraná, Southern Brazil, and correlate them with demographic and epidemiological findings. A retrospective analysis of HIV cases reported from 1999-2007 was also performed. Data from 293 patients were reviewed and 245 were older than 13 (58\% female). The distribution of clades was as follows: B 140 (57\%), C 67 (23\%), F 24 (10\%) and mosaic or unique recombinant forms (URFs) 24 (10\%). Of the 48 patients younger than 13 years of age (62.5\% male), vertical transmission occurred in 46 and the distribution of clades was as follows: B 14 (29\%), C 24 (50\%), F 7 (15\%) and URFs $6(13 \%)$. There was no significant difference in mortality between HIV-1 subtypes. In both groups, patients infected with clade $C$ tended to have higher rates of injection drug use exposure risk.

Key words: HIV - subtypes - genetic variability - HIV exposure

Human immunodeficiency virus (HIV) infection is a global public health problem. Brazil is one of the most affected countries in Latin America by the HIV epidemic, with more than 600,000 people living with the disease (Meira 2002, MS 2005).

Due to the high level of genetic diversity within HIV1 , a classification of the pathogen into groups, subtypes and sub-subtypes was devised (Leitner et al. 2003). Phylogenetic analysis suggested three independent input events of simian immunodeficiency viruses from non-human primates to humans, which established three groups of HIV-1: M (major), O (outlier) and N (Non-M/Non-O). A new strain "P," closely related to the gorilla simian immunodeficiency virus, was described recently in a Cameroonian woman (Plantier et al. 2009). The M group has a global spread and is currently divided into nine pure subtypes (A-D, F-H, J and $\mathrm{K}$ ) and into 48 circulating recombinant forms that are the result of the recombination of pure subtypes (Perrin et al. 2003, Kosakovsky Pond $\&$ Smith 2009). At the nucleotide-level, HIV-1 subtypes have around $70-90 \%$ of sequence identity, whereas the groups showed less than $70 \%$ identify. In addition, HIV-1 and HIV-2 are about 50\% identical (Ariën et al. 2007). On a global scale, multiple HIV-1 strains co-circulate. There is an unequal distribution of viral subtypes in different regions of the world, with some subtypes being found more frequently in certain ethnic groups or forms of transmission. However, subtype $\mathrm{C}$ accounts for approximately $48 \%$ of infections in the entire world (Geretti et al. 2009).

\footnotetext{
+ Corresponding author: sergio.ma@pop.com.br

Received 1 September 2010

Accepted 23 November 2010
}

HIV-1 subtypes present many structural and functional differences which may influence HIV transmission, anti-retroviral (ARV) susceptibility, development of ARV resistance, cellular tropism, organ involvement, disease progression and virus replication (Kantor 2006, Kiwanuka et al. 2008, Geretti et al. 2009). The HIV subtyping has been an important molecular tool for monitoring the geographic changes in the worldwide acquired immune deficiency syndrome (AIDS) epidemic (Requejo 2006). As most studies on ARV response and HIV pathogenesis were carried out with subtype B, it is important to know the distribution of non-B subtypes in all regions and analyze the implications of this diversity in therapy response, diagnostic tests and vaccine development (Moore et al. 2001).

In Brazil, most reports of HIV variability involved samples from patients from the Southeastern Region. Here, subtype $\mathrm{B}$ is most frequently found, followed by subtypes $\mathrm{F} 1, \mathrm{C}$ and recombinant forms of $\mathrm{B} / \mathrm{F} 1$ and $\mathrm{B} / \mathrm{C}$ (Bongertz et al. 2000, Soares et al. 2003, Cabral et al. 2006). However, recent studies of other regions have shown different subtype prevalence, mainly in Southern, Central and Northern Brazil, where an increased proportion of patients are infected by the $\mathrm{C}$ and $\mathrm{F}$ subtypes, respectively (Brindeiro et al. 2003). This variability likely represents distinct entries of the virus into the country and also different sources of infection (Bello et al. 2006, Cabral et al. 2006). The emergence of HIV-1 (likely clade B) in Brazil occurred in the mid-to late 60 s, while the epidemic of subtypes F1 and C appeared in the late $70 \mathrm{~s}$ and early $80 \mathrm{~s}$, respectively (Bello et al. 2006, 2007, 2008, 2009). Studies on HIV infection have shown a distinct distribution of subtypes throughout various regions of the country. Knowledge of clade distributions is essential to describe the course of the referred epidemic in this population and establish preventive and intervening measures tailored to target populations. 
The present study was aimed to report the HIV-1 clade diversity in the state of Paraná (PR), Southern Brazil, and correlate these findings with epidemiological characteristics.

\section{PATIENTS, MATERIALS AND METHODS}

Casuistic - Since 1999, the Brazilian Health Ministry has made genotyping tests to detect virus resistance available to all HIV-infected patients undergoing therapy with virological failure. These tests also help the medical staff to advise changes in medications. Blood samples from the tests are sent to a public reference laboratory. Until 2007, a total of 5,616 exams were performed in Brazil, of which 293 were from patients of PR (MS 2008). All notification forms were revised in the current study. This study was approved by the local ethical review board at the Clinics Hospital of the Federal University of PR.

Methods - A cross-sectional study was carried out with the retrospective analysis of HIV-positive patients who underwent genotype testing from 19992007 at the National Genotyping Network for ARV resistance. Genotyping was carried out in all patients with virological failure using dual or triple-regimen therapy with non-nucleoside reverse transcriptase inhibitors or protease inhibitors, as well as in paediatric patients in early therapy.

Viral resistance genotyping was performed using the commercial system TRUGENE HIV-1 genotyping kit from OpeneGene DNA Sequencing Systems (Siemens Healthcare Diagnostics, USA), following the manufacturer's instructions. HIV-1 subtyping was based on polymerase gene sequences, protease (the whole coding region including nucleotides 10-297) and reverse transcriptase (partial including nucleotides 294-741) regions.
The epidemiological data was investigated for the retrospective review of reporting forms issued by the Information System and Reporting of Injuries sent to the State Health Department of Paraná. The correlation between genotypes and age, gender and risk groups was verified. The following categories of transmission were considered according to the Brazilian Health Ministry classification (MS 2008): injection drug users (IDU), men who have sex with men (MSM), men who have sex with men and women (MSMW), heterosexuals (HETERO), blood transfusion/haemophilic patients, perinatal and ignored.

Statistical analyses - The continuous variables were compared using the Kruskal-Wallis non-parametric test. The groups were compared two-by-two by the Mann-Whitney non-parametric test. The Chi-square test or Fisher's exact test were employed to evaluate possible correlations between HIV-1 subtypes and demographic and epidemiological variables, such as gender, age and risk factors. A p value of 0.05 was defined as statistically significant.

\section{RESULTS}

HIV subtype identification and its correlation with demographic and epidemiological data - During the study period, a total of 293 patients were submitted to genotyping. Subtype B was found in 150 (51.1\%) patients, subtype $\mathrm{C}$ in $65(26.5 \%)$ patients, subtype $\mathrm{F}$ in $31(10.5 \%)$ patients and unique recombinant forms (URFs) in $25(8.5 \%, \mathrm{BC}$, BF1, BA1, F1C and BCF1) patients. Fig. 1 shows the geographic distributions of subtypes in adult patients in distinct regions of PR. Despite a predominance of subtype B, there is an unequal distribution of other subtypes, with a higher proportion of subtype $\mathrm{C}, \mathrm{F}$ and URFs in the western region of the state and subtype $\mathrm{C}$ in the South-eastern Region. In the Northern Region, there is a similar distribution to that observed in the state of São Paulo, South-eastern Brazil.

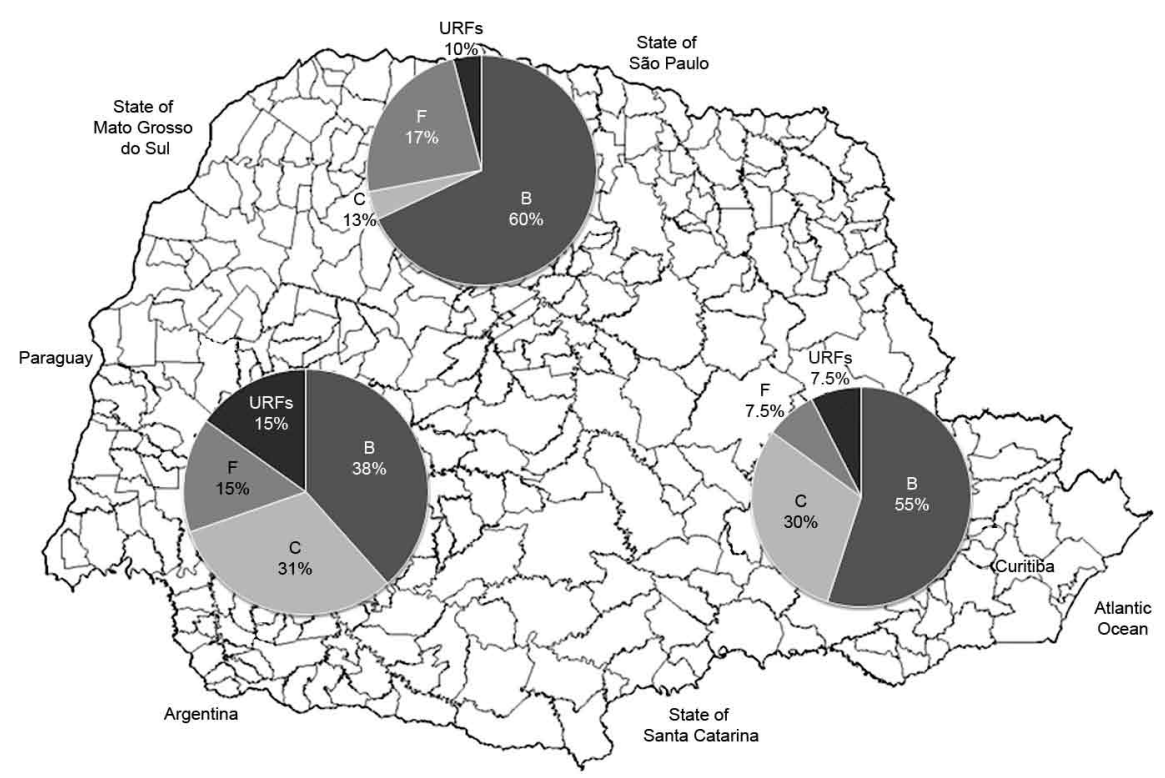

Fig. 1: human immunodeficiency virus-1 clade distribution in the state of Paraná, Brazil, in individuals with age $\geq 13$ years $(\mathrm{n}=245)$. URF: unique recombinant forms. 
The studied population was divided into adult $(\geq$ 13 years old) and paediatric patients $(<13$ years old). Two hundred and five (83.6\%) patients were adults, of which $142(57.9 \%)$ were male, $103(42.1 \%)$ were female and the mean age was $32 \pm 9$ years. When HIV1 subtype distributions were compared between men and women, only subtype B was observed in a higher proportion of men $(p=0.02)$. Fig. 2 shows the distribution of HIV subtypes in adults and paediatric individuals. Analyzing both groups, we observe an important increase of subtype $C$ and URFs among the paediatric population. Among women $\geq 13$ years old, the HIV subtype distribution was B 45 (43.7\%), C 34 (33\%), F 14 (13.6\%) and URF 10 (9.7\%). Among paediatric patients (male and female) the HIV subtype distribution was B 14 (29.2\%), C 22 (45.8\%), F 7 (14.6\%), URF $5(10.4 \%)$ with $\mathrm{p}=0.35$. When the subtypes B and C were compared in both groups, $\mathrm{p}=0.07$.

Concerning the route of contamination, there was no case of seroconversion from accidents with biological materials or from blood transfusion. In the adult patients, a different source of contamination between men and women was observed, according to the subtype analyzed.

Regarding the sexual behaviour of the adult $(\geq$ 13 years) individuals, $185(75.5 \%)$ were HETERO, 35 (14.3\%) MSM and 15 (6.1\%) MSMW. A different subtype frequency was observed between males and females (Fig. 3). The correlation between the HIV subtype with type of exposure between men and
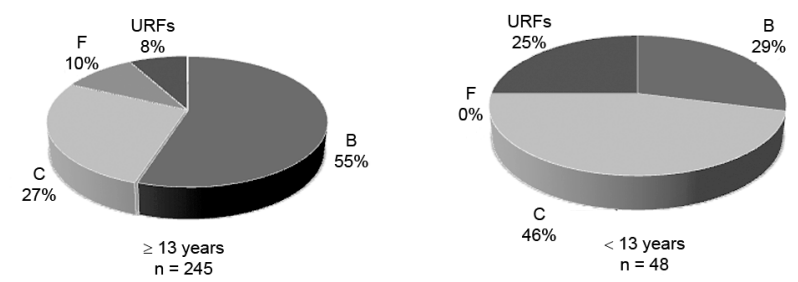

Fig. 2: human immunodeficiency virus clade distribution by age in the state of Paraná, Brazil. URF: unique recombinant forms.

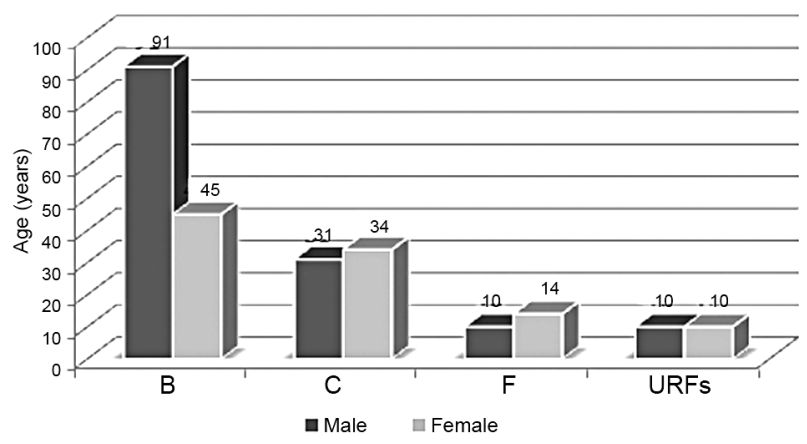

Fig. 3: gender distribution of human immunodeficiency virus-1 clade group aged $\geq 13$ years in the state of Paraná, Brazil. URF: unique recombinant forms. women was different. In this cohort, the females only had sexual relationships with men, regardless of their subtype, and there was no significant difference in the use of intravenous (IV) drugs by subtype ( $p>$ 0.05 ). In contrast, there was a significant difference in IV drug use by subtype among males. The individuals with subtype $\mathrm{C}$ were more likely to use IV drugs (odds ratio $=6.7,95 \%$ confidence interval: 1.82-25.6) . In the adult population, a total of $9.4 \%(23 / 245)$ was IDU. The proportion of IDU and sex behaviour within the male and female adult populations and the subtype distribution are shown in Fig. 4. There was no significant difference in the HIV-1 subtype distribution among the female group $(p=0.612)$, but there was a significant prevalence of subtype $\mathrm{C}$ in the male IDU group $(\mathrm{p}=0.003)$.

Among the $48(16.3 \%)$ paediatric patients, 30 $(62.5 \%)$ were male and the mean age was $34.7 \pm 27.5$ months. Vertical transmission occurred in 46 cases; in two cases, the route of contamination was not reported. The Table shows the distribution of subtypes according to the demographic data.

For the paediatric patients, we analyzed the likely source of contamination from their mothers and their mothers' partners. The sexual behaviour, IV drug use, blood transfusion and history of haemophilia were investigated. In most cases, the answer to these items were rejected or ignored. Among those who responded affirmatively $(25 \%)$ and were infected by HIV-1 clade $C$, there were two mothers $(2 / 22,9 \%)$ and five partners $(5 / 22,23 \%)$ that were IDU. Among those infected by HIV-1 clade B, only two partners were IDU $(2 / 14,14 \%)$. There was no statistical difference between the groups. Concerning the current status of the analyzed adult and paediatric patients, no statistical difference was observed between the subtype distribution and mortality rate.

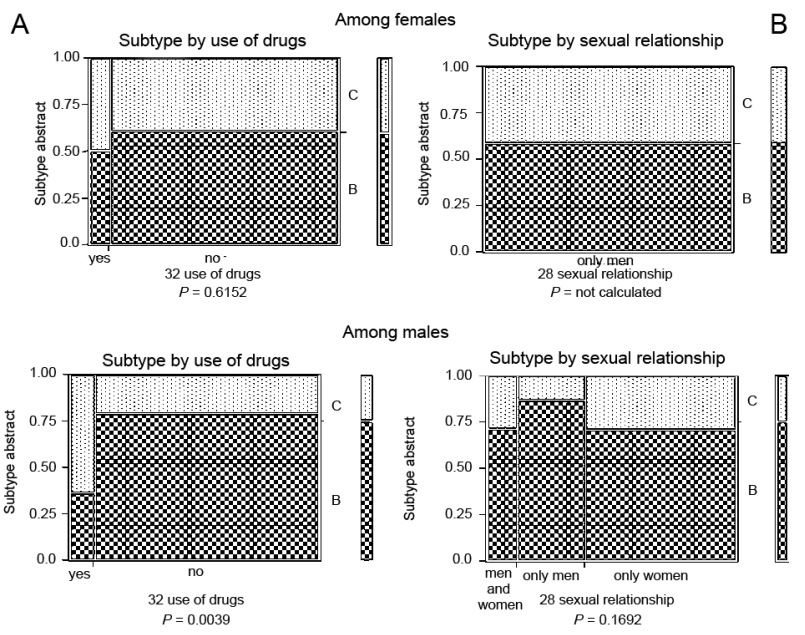

Fig. 4: distribution of human immunodeficiency virus-1 clade according to intravenous drugs users (A) and sexual behaviour (B) between males and females in the group aged $\geq 13$ years $(n=245)$ in the state of Paraná, Brazil. 
TABLE

Demographical and epidemiological data according to HIV-1 clade, state of Paraná, Brazil

\begin{tabular}{|c|c|c|c|c|c|c|c|}
\hline \multirow[t]{3}{*}{$\begin{array}{l}\text { HIV-1 } \\
\text { Subtype }\end{array}$} & \multicolumn{4}{|c|}{$\begin{array}{c}\text { Patients } \geq 13 \text { years old } \\
n=245\end{array}$} & \multicolumn{3}{|c|}{$\begin{array}{l}\text { Patients }<13 \text { years old } \\
\mathrm{n}=48\end{array}$} \\
\hline & \multirow{2}{*}{$\begin{array}{c}\mathrm{n} \\
\text { Gender }(\mathrm{M} / \mathrm{F}) \\
\mathrm{p} \text { value }\end{array}$} & \multirow[b]{2}{*}{$\begin{array}{l}\text { Age (years) } \\
(\text { mean } \pm \mathrm{SD})\end{array}$} & \multicolumn{2}{|r|}{ Risk factor } & \multirow{2}{*}{$\begin{array}{c}\mathrm{n} \\
\text { Gender }(\mathrm{M} / \mathrm{F}) \\
\mathrm{p} \text { value }\end{array}$} & \multirow[b]{2}{*}{$\begin{array}{l}\text { Age (months) } \\
(\text { mean } \pm \mathrm{SD})\end{array}$} & \multirow{2}{*}{$\begin{array}{c}\text { Risk group } \\
\text { (vertical transmission/ } \\
\text { UNKNOWN) }\end{array}$} \\
\hline & & & IDU & $\begin{array}{c}\text { Sexual } \\
\text { behaviour }\end{array}$ & & & \\
\hline B & $\begin{array}{c}136 \\
91 / 45 \\
p=0.02\end{array}$ & $32 \pm 7.5$ & 7 & $\begin{array}{c}\text { HETERO }=93 \\
\text { MMMW }=37 \\
\text { UNKNOWN }=6\end{array}$ & $\begin{array}{c}14 \\
8 / 6 \\
p>0.05\end{array}$ & $38 \pm 25.9$ & $13 / 1$ \\
\hline $\mathrm{C}$ & $\begin{array}{c}65 \\
31 / 34 \\
p>0.05\end{array}$ & $33 \pm 8.4$ & 10 & $\begin{array}{c}\text { HETERO }=54 \\
\text { MMMW }=8 \\
\text { UNKNOWN = } 3\end{array}$ & $\begin{array}{c}22 \\
16 / 6 \\
p>0.05\end{array}$ & $34.4 \pm 22.6$ & $21 / 1$ \\
\hline $\mathrm{F}$ & $\begin{array}{c}24 \\
10 / 14 \\
p>0.05\end{array}$ & $35 \pm 9.2$ & 4 & $\begin{array}{c}\text { HETERO = } 19 \\
\text { MMMW = 4 } \\
\text { UNKNOWN = } 1\end{array}$ & $\begin{array}{c}7 \\
3 / 4 \\
\mathrm{p}>0.05\end{array}$ & $24.6 \pm 16.1$ & $7 / 0$ \\
\hline URFs & $\begin{array}{c}20 \\
10 / 10 \\
p>0.05\end{array}$ & $35 \pm 8.8$ & 2 & $\begin{array}{c}\text { HETERO }=19 \\
\text { MMMW }=1 \\
\text { UNKNOWN }=0\end{array}$ & $\begin{array}{c}5 \\
3 / 2 \\
p>0.05\end{array}$ & $41.2 \pm 58.2$ & $5 / 0$ \\
\hline
\end{tabular}

F: female; HETERO: heterosexual; IDU: injection drug user; M: male; MMMW: men who have sex with man and women; SD: standard deviation; URFs: unique recombinant forms.

\section{DISCUSSION}

Similar to other studies conducted in different geographical regions of Brazil, the HIV epidemic in PR shows considerable clade diversity. Subtype B was found to be the most prevalent clade in this study (Bongertz et al. 2000, Brindeiro et al. 2003, Cabral et al. 2006, Locateli et al. 2007, Dias et al. 2009). However, analysis of the data in different age groups showed a change in the prevalence of subtypes, with subtype $\mathrm{C}$ being more frequently found in paediatric patients. It is important to stress that we analyzed populations infected at different times; in adults only those experiencing virological failure underwent genotyping, whereas the paediatric patients underwent genotype tests prior to the therapy. As the subtypes found in children were the same subtype found in their mothers, we observed a change in the newly infected population profile, with a higher prevalence of subtype C and IV drug use as the likely source of contamination. As clade subtyping was based on ARV resistance testing, the results of this study are likely applicable only to individuals with more advanced disease who require $\mathrm{ARV}$ therapy. Clade $\mathrm{C}$ was more frequent in the group of patients $<13$ years old and represents more recently infected patients, indicating an increase in clade $\mathrm{C}$ frequency in PR. In addition, the majority of HIV positive pregnant women carries the virus but do not have AIDS, enhancing the possibility of a recent infection.
Paediatric populations could represent more recent infections than adult populations with highly active ARV therapy treatment failure. However, we are not able to estimate temporal trends of HIV-1 subtypes by directly comparing both populations. We observed that there are different subtype distributions between males and females and that the HIV subtype found in children reflects the subtype found in their mothers. Also, we observed that there is a higher proportion of subtype $\mathrm{C}$ among IDUs and the frequency of IDUrelated transmission among the paediatric population $(23 \%)$ is higher than among the adult population $(9 \%)$. Although we do find a significant trend $(p=0.07)$ when we look at subtypes B and C in the female adult population compared to the paediatric population, it is important to highlight that the higher frequency of clade $\mathrm{C}$ among paediatric patients compared to adults could also be explained by the association between subtype C, female sex and IDU. However, in agreement with our findings, Ferreira et al. (2008) reported a $53 \%$ prevalence of HIV-1 clade B and a $30 \%$ prevalence of clade $\mathrm{C}$ in a study carried out in recently infected male patients from Curitiba. These data suggest an increase of subtype $\mathrm{C}$ frequency over time. Also, Toledo et al. (2010) had similar results when they reported the HIV-1 subtype profile from adult patients in failure therapy in PR. Clade B was found in $61 \%$ of cases and clade $\mathrm{C}$ in $20 \%$ of the cases. However, an increased frequency of subtype $\mathrm{C}$ was observed in 
women compared to men $(32 \%$ vs. $14 \%, \mathrm{p}<0.05)$. In the present study, a correlation between HIV-1 subtype and age was observed, with a higher frequency of clade $\mathrm{C}$ in recently infected patients.

Previous studies have reported a higher prevalence of subtype C in Southern Brazil. A study carried out in the state of Santa Catarina showed a prevalence of $48 \%$ of subtype $\mathrm{C}$ and $23 \%$ of subtype $\mathrm{B}$, whereas in the state of Rio Grande do Sul (RS), HIV-1 clade C was observed in $29 \%$ of cases and HIV-1 B in $22.6 \%$ of cases (Brindeiro et al. 2003, Locateli et al. 2007, Dias et al. 2009). Our findings corroborate these reports, clearly showing a change in the subtype profile of this region.

The distribution of HIV clades in adult patients in different regions of PR showed a similar prevalence between subtype $\mathrm{B}$ and $\mathrm{C}$ in the western region of the state. Here, subtype B accounted for $38 \%$ of the cases and subtype $\mathrm{C}$ accounted for $31 \%$ of the cases. However, studies on HIV-1 strains have demonstrated that different dissemination rates exist in the border regions of Southern Brazil. In areas such as the southeast region of Brazil, Argentina, Paraguay and Uruguay, the prevalence of subtype $\mathrm{C}$ remains below $6 \%$. The subtype distributions most likely reflect the most prevalent transmission routes rather than the distinct in-strain infectivity (Bello et al. 2009). Nevertheless, these questions can only be answered by understanding pathogen evolution, dynamics and spread within the population at large and within infected hosts (Ariën et al. 2007).

In PR, around 26,000 AIDS/HIV infected patients were notified until June 2009. Most of these patients live in Curitiba, the state capital, and in the metropolitan region. These areas have an average of 16.8 cases $/ 100,000$ inhabitants and sentinel studies have shown a prevalence rate of around $0.6 \%$ HIV positivity in Curitiba (MS 2009). Epidemiological studies reveal a change in the profile of HIV-infected patients, with an increase in HETERO, women and people with lower income. Following a change in patient profile, there is also a change in the genotypes of viruses with an increased prevalence of certain subtypes. Thus, it is important to determine the consequences of these changes in terms of the response to therapy, immunology, vaccine and survival (Soares et al. 2003).

Studies on AIDS/HIV carried out since the initial HIV epidemic have demonstrated great viral genetic diversity, probably reflecting viral phenotype. The predominance of subtype $\mathrm{C}$ is likely related to the decreased virulence of this subtype. Consequently, a greater number of infected individuals survive and further spread the infection (Ariën et al. 2007). The displacement of subtype B has been demonstrated in other countries and probably occurred due to the introduction of subtype $\mathrm{C}$ into the population through a different route of contamination. However, some studies have reported that subtype $\mathrm{C}$ predominance in certain risk groups was reduced during the epidemic (Ariën et al. 2007).

The rapid initial growth rate of some HIV-1 subtypes displayed a higher fitness and/or virus transmissibility. Alternatively, variations in the initial growth rate of
HIV-1 variants may reflect differences in the susceptible populations that characterized the initial spread of each strain. The HIV-1C strains have been associated with heterosexual contact. In this study, we demonstrate the high prevalence of this clade among women. However, when we analyzed these women's partners, we detected a high prevalence of IV drug users. Studies carried out with samples from RS have shown that after the initial period of fast exponential growth, the expansion rate of clade C epidemics has slowed since the early 2000s (Bello et al. 2009). However, this study was only performed with samples from one state, and may not represent the pattern of other states (Bello et al. 2009). We must determine if these changes in the demographic pattern are the consequences of introducing preventive measures or the results of a saturation of high-risk transmission networks (Bello et al. 2010).

This report offers insight into the dynamics of the HIV spread in the Brazilian population. This is the first study that shows the prevalence of different HIV clades in distinct regions of PR. We aimed to identify modes of transmission and risk factors, while taking into consideration the genetic diversity of HIV-1 in all of the Brazilian regions. The correlation of HIV subtypes with demographic and epidemiological data is critical to determine the correct preventative measures. Further studies on global HIV genetic variability are necessary, not only for the understanding of viral origins and evolution, but also for the consequences of this variability in the performance of diagnostic tests and in the response to ARV therapy and vaccination.

\section{ACKNOWLEDGEMENTS}

To the RENAGENO, for technical support.

\section{REFERENCES}

Ariën KK, Vanham G, Arts EJ 2007. Is HIV-1 evolving to a less virulent form in humans? Nat Rev Microbiol 5: 141-151.

Bello G, Aulicino PC, Ruchansky D, Guimarães ML, Lopez-Galindez C, Casado C, Chiparelli H, Rocco C, Mangano A, Sen L, Morgado MG 2010. Phylodynamics of HIV-1 circulating recombinant forms 12_BF and 38_BF in Argentina and Uruguay. Retrovirology 7: 22.

Bello G, Eyer-Silva WA, Couto-Fernandez JC, Guimarães ML, Chequer-Fernandez SL, Teixeira SL, Morgado MG 2007. Demographic history of HIV-1 subtypes B and F in Brazil. Infect Genet Evol 7: 263-270.

Bello G, Guimarães ML, Morgado MG 2006. Evolutionary history of HIV-1 subtype B and F infections in Brazil. AIDS 20: 763-768.

Bello G, Guimarâes ML, Passaes CP, Matos Almeida SE, Veloso VG, Morgado MG 2009. Short communication: evidences of recent decline in the expansion rate of the HIV type 1 subtype $\mathrm{C}$ and CRF31_BC epidemics in southern Brazil. AIDS Res Hum Retroviruses 25: 1065-1069.

Bello G, Passaes CP, Guimarães ML, Lorete RS, Matos Almeida SE, Medeiros RM, Alencastro PR, Morgado MG 2008. Origin and evolutionary history of HIV-1 subtype C in Brazil. AIDS 22: 1993-2000.

Bongertz V, Bou-Habib DC, Brígido LF, Caseiro M, Chequer PJ, Couto-Fernandez JC, Ferreira PC, Galvão-Castro B, Greco D, Guimarães ML, Linhares de Carvalho MI, Morgado MG, Oliveira CA, Osmanov S, Ramos CA, Rossini M, Sabino E, Tanuri A, Ueda M 2000. HIV-1 diversity in Brazil: genetic, biologic, and immu- 
nologic characterization of HIV-1 strains in three potential HIV vaccine evaluation sites. Brazilian Network for HIV Isolation and Characterization. J Acquir Immune Defic Syndr 23: 184-193.

Brindeiro RM, Diaz RS, Sabino EC, Morgado MG, Pires IL, Brigido L, Dantas MC, Barreira D, Teixeira PR, Tanuri A, Brazilian Network for Drug Resistance Surveillance 2003. Brazilian Network for HIV Drug Resistance Surveillance (HIV-BResNet): a survey of chronically infected individuals. AIDS 17: 1063-1069.

Cabral VP, Cunha CB, Magalhaes EFL, Pinto-Neto LF, Couto-Fernandez JC, Dietze R, Morgado MG, Ribeiro-Rodrigues R 2006. Human immunodeficiency virus type-1 subtypes of infected patients in Espírito Santo, Brazil. Mem Inst Oswaldo Cruz 101: 881-885.

Dias CF, Nunes CC, Freitas IO, Lamego IS, Oliveira IM, Gilli S, Rodrigues R, Brigido LF 2009. High prevalence and association of HIV-1 non-B subtype with specific sexual transmission risk among antiretroviral naïve patients in Porto Alegre, RS, Brazil. Rev Inst Med Trop Sao Paulo 51: 191-196.

Ferreira JLP, Thomaz M, Rodrigues R, Harrad D, Oliveira CM, Oliveira CAF, Batista JPG, Ito TS, Brigido LFM 2008. Molecular characterisation of newly identified HIV-1 infections in Curitiba, Brazil: preponderance of clade $\mathrm{C}$ among males with recent infections. Mem Inst Oswaldo Cruz 103: 800-808.

Geretti AM, Harrison L, Green H, Sabin C, Hill T, Fearnhill E, Pillay D, Dunn D, UK Collaborative Group on HIV Drug Resistance 2009. Effect of HIV-1 subtype on virologic and immunologic response to starting highly active antiretroviral therapy. Clin Infect Dis 48: 1296-1305.

Kantor R 2006. Impact of HIV-1 pol diversity on drug resistance and its clinical implications. Curr Opin Infect Dis 19: 594-606.

Kiwanuka N, Laeyendecker O, Robb M, Kigozi G, Arroyo M, McCutchan F, Eller LA, Eller M, Makumbi F, Birx D, Wabwire-Mangen F, Serwadda D, Sewankambo NK, Quinn TC, Wawer M, Gray R 2008. Effect of human immunodeficiency virus Type 1 (HIV-1) subtype on disease progression in persons from Rakai, Uganda, with incident HIV-1 infection. J Infect Dis 197: 707-713.

Kosakovsky Pond SL, Smith DM 2009. Are all subtypes created equal? The effectiveness of antiretroviral therapy against nonsubtype B HIV-1. Clin Infect Dis 48: 1306-1309.

Leitner T, Foley B, Hahn BH, Marx P, McCutchan F, Mellors JW, Wolinsky S, Korber B 2003. HIV Sequence Compendium 2003,
Theoretical Biology and Biophysics Group, Los Alamos National Laboratory, Los Alamos, NM, LA-UR 04-7420.

Locateli D, Stoco PH, de Queiroz AT, Alcântara LC, Ferreira LG, Zanetti CR, Rodrigues R, Grisard EC, Pinto AR 2007. Molecular epidemiology of HIV-1 in Santa Catarina state confirms increases of subtype $\mathrm{C}$ in Southern Brazil. J Med Virol 79: $1455-1463$.

Meira DA 2002. Acquired immunodeficiency syndrome in Brazil. Croat Med J 43: 475-479.

Moore JP, Parren PW, Burton DR 2001. Genetic subtypes, humoral immunity, and human immunodeficiency virus type 1 vaccine development. J Virol 75: 5721-5729.

MS - Ministério da Saúde, Brasil 2005. Programa Nacional de DST/ AIDS BMoH. Epidemiologic bulletin - AIDS II: 1. Available from: http://www.aids.gov.br/sites/default/files/arquivos_anexos/ BOLETIM.pdf. (accessed Aug 31 2010).

MS - Ministério da Saúde, Brasil 2008. Programa Nacional de DST/ AIDS BMoH. Epidemiologic bulletin - AIDS V: 1 Available from: http://www.aids.gov.br/sites/default/files/Boletim2008 versao1_6.pdf (accessed Dec 07 2010).

MS - Ministério da Saúde, Brasil 2009. Programa Nacional de DST/ AIDS BMoH. Epidemiologic bulletin - AIDS VI: 1. Preliminary version. Available from: http://www.aids.gov.br/data/Pages/LUMIS624DE984PTBRIE.htm. (accessed Nov 25 2009).

Perrin L, Kaiser L, Yerly S 2003. Travel and the spread of HIV-1 genetic variants. Lancet Infect Dis 3: 22-27.

Plantier JC, Leoz M, Dickerson JE, De Oliveira F, Cordonnier F, Lemée V, Damond F, Robertson DL, Simon F 2009. A new human immunodeficiency virus derived from gorillas. Nat Med 15: $871-872$

Requejo HI 2006. Worldwide molecular epidemiology of HIV. Rev Saude Publica 40: 331-345.

Soares MA, De Oliveira T, Brindeiro RM, Diaz RS, Sabino EC, Brigido L, Pires IL, Morgado MG, Dantas MC, Barreira D, Teixeira PR, Cassol S, Tanuri A, Brazilian Network for Drug Resistance Surveillance 2003. A specific subtype C of human immunodeficiency virus type 1 circulates in Brazil. AIDS 17: 11-21.

Toledo PV, de Carvalho DS, de Rossi SG, Brindeiro R, de QueirozTelles F 2010. Genetic diversity of human immunodeficiency virus-1 isolates in Paraná, Brazil. Braz J Infect Dis 14: 230-236. 